\title{
The relationship between cerebral regional oxygen saturation during extracorporeal cardiopulmonary resuscitation and the neurological outcome in a retrospective analysis of 16 cases
}

Naoki Ehara ${ }^{1}$, Tomoya Hirose ${ }^{2 *}$, Tadahiko Shiozaki ${ }^{2}$, Akinori Wakai ${ }^{1}$, Tetsuro Nishimura ${ }^{1}$, Nobuto Mori², Mitsuo Ohnishi ${ }^{2}$ Daikai Sadamitsu' and Takeshi Shimazu²

\begin{abstract}
Background: In recent years, the measurement of cerebral regional oxygen saturation $\left(\mathrm{rSO}_{2}\right)$ during resuscitation has attracted attention. The objective of this study was to clarify the relationship between the serial changes in the cerebral $\mathrm{rSO}_{2}$ values during extracorporeal cardiopulmonary resuscitation (ECPR) and the neurological outcome.

Methods: We measured the serial changes in the cerebral $\mathrm{rSO}_{2}$ values of patients with out-of-hospital cardiac arrest before and after ECPR in Osaka National Hospital.

Results: From January 2013 through March 2015, the serial changes in the cerebral $\mathrm{rSO}_{2}$ values were evaluated in 16 patients. Their outcomes, as measured by the Glasgow Outcome Scale (GOS) score at discharge, included good recovery (GR) $(n=4)$, vegetative state (VS) $(n=2)$, and death (D) $(n=10)$. In the poor neurological group (VS and D: $n=12$; age, $52.8 \pm 4.0$ years), the cerebral $\mathrm{rSO}_{2}$ values showed a significant increase during ECPR ( 5 min before ECPR: $52.0 \pm 1.8 \% ; 2$ min before ECPR: $56.1 \pm 2.3 \% ; 2$ min after ECPR: $63.5 \pm 2.2 \% ; 5$ min after ECPR: $66.4 \pm 2.2 \%$; 10 min after ECPR: $67.6 \pm 2.3 \%[P<0.01]$ ). In contrast, in the good neurological group (GR: $n=4$; age, $53.8 \pm 6$. 9 years), the cerebral $\mathrm{rSO}_{2}$ values did not increase to a significant extent during ECPR ( 5 min before ECPR: $61.9 \pm 3$. 1\%; 2 min before ECPR: $57.1 \pm$ 4.0\%; 2 min after ECPR: $59.6 \pm 3.8 \% ; 5$ min after ECPR: $61.0 \pm 3.7 \% ; 10$ min after ECPR: $62.0 \pm 3.8 \%[P=0.88]$ ). Our study suggested that the patients whose cerebral $\mathrm{rSO}_{2}$ values showed no significant improvement after ECPR might have had a good neurological prognosis.
\end{abstract}

Conclusions: The serial changes in the cerebral $\mathrm{rSO}_{2}$ values during ECPR may predict a patient's neurological outcome. The further evaluation of the validity of $\mathrm{rSO}_{2}$ monitoring during ECPR may lead to a new resuscitation strategy.

Keywords: Cerebral regional oxygen saturation, Extracorporeal cardiopulmonary resuscitation, Neurological outcome, Out-of-hospital cardiac arrest, Near-infrared spectroscopy

\footnotetext{
*Correspondence: htomoya1979@hp-emerg.med.osaka-u.ac.jp

${ }^{2}$ Department of Traumatology and Acute Critical Medicine, Osaka University

Graduate School of Medicine, 2-15 Yamadaoka, Suita, Osaka 565-0871, Japan

Full list of author information is available at the end of the article
} 


\section{Background}

Sudden cardiac arrest is one of the most important causes of death and an important public health problem in the industrialised world [1]. However, survival from out-of-hospital cardiac arrest (OHCA) is still low [2], and to improve it, we think that a new resuscitation strategy is needed.

In recent years, the measurement of cerebral regional oxygen saturation $\left(\mathrm{rSO}_{2}\right)$ by near-infrared spectroscopy (NIRS) during resuscitation has attracted attention. We have already reported the serial changes in the cerebral $\mathrm{rSO}_{2}$ values during resuscitation in patients with OHCA [3]. Chest compression alone could not increase the cerebral $\mathrm{rSO}_{2}$ value, which was found to gradually increase with a return of spontaneous circulation (ROSC). The cerebral $\mathrm{rSO}_{2}$ value also increased promptly after the initiation of extracorporeal cardiopulmonary resuscitation (ECPR) [4]. However, we could not predict the neurological outcome by evaluating the cerebral $\mathrm{rSO}_{2}$ value in patients with OHCA in 2010 [4].

It is challenging to predict the neurological outcome following OHCA. Although some researchers have reported that the cerebral $\mathrm{rSO}_{2}$ value at hospital arrival can predict the neurological outcome in patients with OHCA [5-7], we thought that this conclusion was incorrect. Because the $\mathrm{rSO}_{2}$ values always change depending on the patient's situation at the time when the cerebral $\mathrm{rSO}_{2}$ is measured $[4,8]$, we hypothesise that the serial change in the $\mathrm{rSO}_{2}$ values is important rather than a single measured value.

By chance, we detected a difference in the way the values of cerebral $\mathrm{rSO}_{2}$ in patients with $\mathrm{OHCA}$ changed before and after the application of ECPR. Thus, the objective of this study was to clarify the relationship between the serial changes in the cerebral $\mathrm{rSO}_{2}$ value during ECPR and the neurological outcome.

\section{Methods}

\section{Study design and data collection}

This retrospective study was approved by the Ethics Committee of National Hospital Organization Osaka National Hospital (Osaka, Japan). The subjects were all cardiopulmonary arrest (CPA) patients who were transferred to National Hospital Organization Osaka National Hospital by emergency life-saving technicians (ELTs). At the emergency department, a sensor was attached to the patient's forehead to continuously monitor the cerebral $\mathrm{rSO}_{2}$ value during resuscitation. ELTs and medical staff performed cardiopulmonary resuscitation according to the recommendations of the Japan Resuscitation Council Guidelines 2010, which were based on the American Heart Association and the International Liaison Committee on Resuscitation guidelines [9]. The medical staff could see the $\mathrm{rSO}_{2}$ values during resuscitation, and the values were automatically recorded. However, they did not change the treatment according to the cerebral $\mathrm{rSO}_{2}$ data. We retrospectively collected and analysed data from the CPA patients undergoing ECPR.

The variables that were analysed included the age, sex, initial rhythm, whether the OHCA was witnessed, and whether a bystander performed cardiopulmonary resuscitation (CPR). We evaluated the patient's cerebral $\mathrm{rSO}_{2}$ values at 5 and $2 \mathrm{~min}$ before the application of ECPR and at 2, 5, and $10 \mathrm{~min}$ after the application of ECPR. The neurological prognosis was evaluated according to the Glasgow Outcome Scale (GOS) score. The normal range of cerebral $\mathrm{rSO}_{2}$ was determined from 15 healthy adult volunteers whose values were measured on room air.

\section{The NIRS-based $\mathrm{rSO}_{2}$ monitoring system}

An $\mathrm{rSO}_{2}$ monitor (TOS-OR; TOSTEC Co., Tokyo, Japan) was used to measure the cerebral $\mathrm{rSO}_{2}$ value. The monitor measures the oxygen saturation based on the Beer-Lambert law, using three different wavelengths of near-infrared LED light, which have specific absorbance in oxyhaemoglobin and deoxyhaemoglobin. The lights pass through the skin to a depth of approximately $3 \mathrm{~cm}$, and the reflected lights are sensed by a photodiode. The reflected lights mainly represent the haemoglobin information in the cerebral cortex. The system can measure $\mathrm{rSO}_{2}$ data every second without the need for pulsation. It is therefore possible to continuously monitor the $\mathrm{rSO}_{2}$ values of CPA patients.

\section{Data analysis}

Two $\mathrm{rSO}_{2}$ values (on the left side and right side) were acquired continuously. The average of these two values was then calculated. If the value of one of the two values appeared to be in error, then the other value was used for the data analysis. Finally, graphs were drawn of the serial changes in the cerebral $\mathrm{rSO}_{2}$ values.

\section{Statistical analysis}

All of the data are represented as the mean \pm standard deviation (SD). The Wilcoxon rank sum test was used to compare the differences between the two groups at each measurement point. A one-way repeated-measures analysis of variance (ANOVA) was used to evaluate the differences among the measured points. $P$ values of $<0.05$ were considered to indicate statistical significance. All of the statistical analyses were performed using the JMP Pro 11 for Windows software program (SAS Institute Inc., Cary, NC, USA).

\section{Results}

Normal range of cerebral $\mathrm{rSO}_{2}$

The normal range of cerebral $\mathrm{rSO}_{2}$ in the healthy adult volunteers $(n=15$; age, $43.2 \pm 8.9$ years; 10 men and 5 women) was $71.2 \pm 3.9 \%$ (on room air). 


\section{Patient characteristics}

From January 2013 through March 2015, the serial changes in the cerebral $\mathrm{rSO}_{2}$ values of 16 patients were evaluated. Their outcomes, as measured by the GOS score at discharge, included a good recovery $(\mathrm{GR})(n=$ $4)$, vegetative state (VS) $(n=2)$, and death (D) $(n=10)$. The time from the onset of cardiac arrest to the initiation of ECPR did not differ to a statistically significant extent between the poor neurological group (VS and D: $64.6 \pm 22.6 \mathrm{~min}$ ) and the good neurological group (GR: $49.5 \pm 5.7 \mathrm{~min})(P=0.11)$. The characteristics of the patients with OHCA are shown in Table 1.

The relationship between the cerebral $\mathrm{rSO}_{2}$ values during ECPR and the neurological outcome

The serial changes in the cerebral $\mathrm{rSO}_{2}$ values during ECPR for each patient are shown in Fig. 1. The serial changes in the mean cerebral $\mathrm{rSO}_{2}$ value during ECPR in the good and poor neurological outcome groups are shown in Fig. 2. The only significant difference in the cerebral $\mathrm{rSO}_{2}$ values of the two groups was observed at 5 min before ECPR $(P<0.05)(2 \mathrm{~min}$ before ECPR: $P=$ 0.95; 2 min after ECPR: $P=0.36 ; 5$ min after ECPR: $P=$ 0.20 ; and $10 \mathrm{~min}$ after ECPR: $P=0.21$ ). In the poor neurological group (VS and $\mathrm{D}: n=12$; age, $52.8 \pm$ 4.0 years), the cerebral $\mathrm{rSO}_{2}$ values increased significantly during ECPR ( $5 \mathrm{~min}$ before ECPR: $52.0 \pm 1.8 \%$; 2 min before ECPR: $56.1 \pm 2.3 \%$; 2 min after ECPR: 63.5 $\pm 2.2 \%$; 5 min after ECPR: $66.4 \pm 2.2 \%$; and $10 \mathrm{~min}$ after

Table 1 The characteristics of the patients with out-of-hospital cardiac arrest

\begin{tabular}{|c|c|c|}
\hline & $\begin{array}{l}\text { Good neurological } \\
\text { outcome group } \\
\text { (GR) }\end{array}$ & $\begin{array}{l}\text { Poor neurological } \\
\text { outcome group } \\
\text { (VS and D) }\end{array}$ \\
\hline Number & 4 & 12 \\
\hline Age $( \pm S D)$ (years) & $53.8 \pm 6.9$ & $52.9 \pm 4.0$ \\
\hline Male (\%) & $4(100 \%)$ & $10(83.3 \%)$ \\
\hline \multicolumn{3}{|l|}{ Initial rhythm } \\
\hline VF (\%) & $4(100 \%)$ & $6(50.0 \%)$ \\
\hline PEA (\%) & 0 & $4(33.3 \%)$ \\
\hline Asystole (\%) & 0 & $2(16.7 \%)$ \\
\hline \multicolumn{3}{|l|}{ Witnessed } \\
\hline Yes (\%) & $4(100 \%)$ & 11 (91.7\%) \\
\hline No (\%) & 0 & $1(8.3 \%)$ \\
\hline \multicolumn{3}{|l|}{ Bystander CPR } \\
\hline Yes (\%) & $4(100 \%)$ & 10 (83.3\%) \\
\hline No (\%) & 0 & $2(16.7 \%)$ \\
\hline $\begin{array}{l}\text { The time from the onset of } \\
\text { cardiac arrest to the initiation of } \\
\text { ECPR (min) }\end{array}$ & $49.5 \pm 5.7$ & $64.6 \pm 22.6$ \\
\hline
\end{tabular}

CPR cardiopulmonary resuscitation, $D$ death, GR good recovery, PEA pulseless electrical activity, VF ventricular fibrillation, VS vegetative state
ECPR: $67.6 \pm 2.3 \%[P<0.01]$ ) (Figs. 1a and 2). In contrast, in the good neurological group (GR: $n=4$; age, $53.8 \pm 6.9$ years), the cerebral $\mathrm{rSO}_{2}$ values did not increase to a statistically significant extent during ECPR (5 min before ECPR: $61.9 \pm 3.1 \%$; 2 min before ECPR: $57.1 \pm 4.0 \%$; 2 min after ECPR: $59.6 \pm 3.8 \%$; 5 min after ECPR: $61.0 \pm 3.7 \%$; and $10 \mathrm{~min}$ after ECPR: $62.0 \pm 3.8 \%$ $[P=0.88]$ ) (Figs. 1b and 2).

\section{Discussion}

Recently, a systematic review and meta-analysis reported by Sanfilippo et al. [10] showed that higher initial and average cerebral $\mathrm{rSO}_{2}$ values were both associated with a greater chance of achieving an ROSC in patients with cardiac arrest; however, they could not show a relationship between the cerebral $\mathrm{rSO}_{2}$ value and the neurological outcome of patients resuscitated from cardiac arrest. Both Ito et al. [5] and Storm et al. [11] revealed significantly higher cerebral $\mathrm{rSO}_{2}$ values on hospital arrival in patients with a good neurological outcome, but the cerebral $\mathrm{rSO}_{2}$ values of the good and poor outcome groups varied widely and there was a large amount of overlap. We hypothesised that a single measurement of cerebral value might not be important because the $\mathrm{rSO}_{2}$ values always change depending on the patient's situation at the time of the $\mathrm{rSO}_{2}$ measurement $[4,8]$. Therefore, we think that the value of NIRS should be assessed by trend value, not by absolute value.

Counterintuitively, the results of this study suggested that the patients whose cerebral $\mathrm{rSO}_{2}$ values did not show a significant improvement after ECPR might have had a good neurological prognosis (Figs. 1b and 2). We thought that, in the good neurological group, the brain blood flow was recovered by ECPR, the oxygen was delivered to brain tissue, and the brain tissue might start to consume oxygen. These events continuously change. So, we believe that the most important factor when evaluating the cerebral $\mathrm{rSO}_{2}$ value during resuscitation to predict the neurological outcome is serial change in the cerebral $\mathrm{rSO}_{2}$ values. Two reports have shown a significant increase in the cerebral $\mathrm{rSO}_{2}$ value after the application of ECPR in patients with OHCA; however, all of the reported patients had a poor neurological outcome or died $[4,12]$. One report showed that the tissue oxygen index decreased in a patient with a favourable neurological outcome $(n=1)$ but that it did not change in patients with unfavourable neurological outcome $(n=$ 14) [13]. These reports also failed to show a relationship between the cerebral $\mathrm{rSO}_{2}$ value during ECPR and the neurological outcome.

We hypothesised that the cerebral $\mathrm{rSO}_{2}$ values of the patients in the good neurological outcome group did not change before or after ECPR because their brain tissue might have been consuming oxygen; therefore, we began 

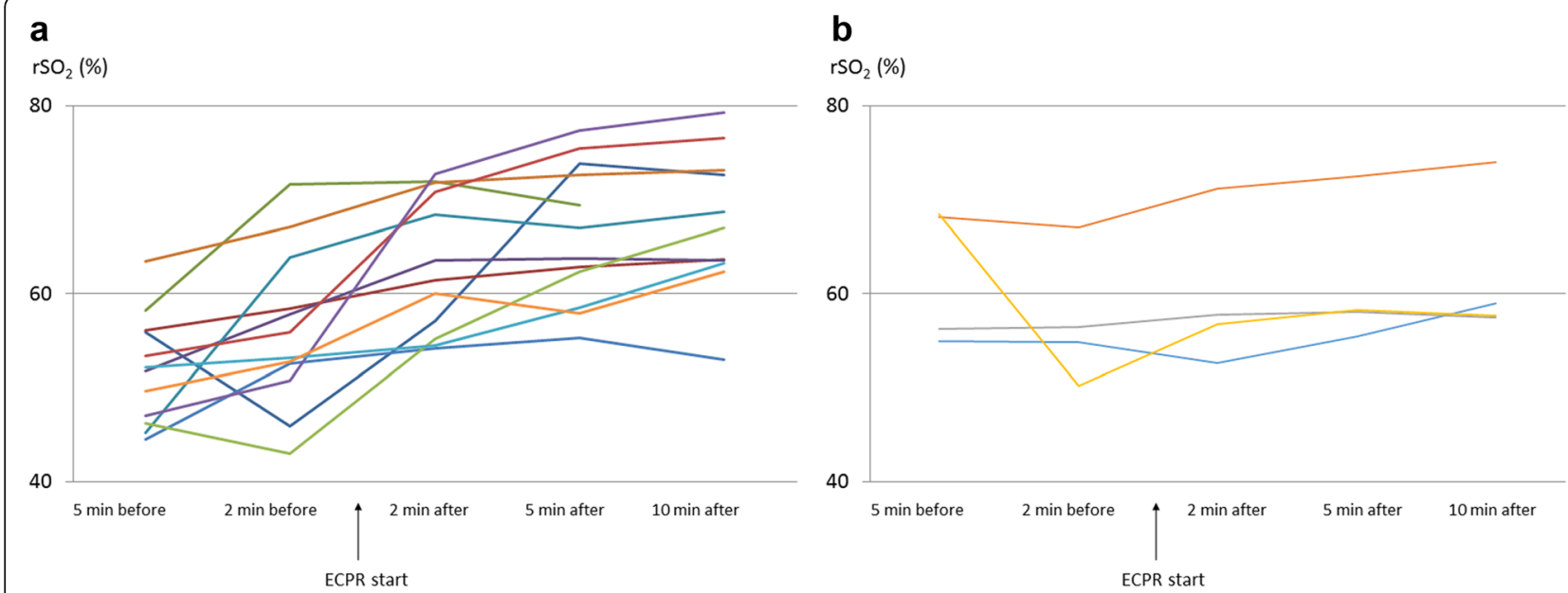

Fig. 1 The serial change in the cerebral regional oxygen saturation $\left(\mathrm{rSO}_{2}\right)$ of each patient during extracorporeal cardiopulmonary resuscitation (ECPR). a The poor neurological outcome group $(n=12)$ and $\mathbf{b}$ the good neurological outcome group $(n=4)$

to evaluate the cerebral $\mathrm{rSO}_{2}$ value during intensive care unit (ICU) treatment after the ROSC. In Fig. 3, we show one patient with an ROSC who displayed a decreasing cerebral $\mathrm{rSO}_{2}$ value but who experienced a GR. When we started to perform cerebral $\mathrm{rSO}_{2}$ measurement in this patient, his cerebral $\mathrm{rSO}_{2}$ value was $66 \%$, and it gradually dropped to $57 \%$ after $12 \mathrm{~min}$. His neurological outcome was good. We think that the ROSC led to the recovery of the cerebral blood flow, and because in patients with a good neurological outcome oxygen consumption might increase, as a result, his cerebral $\mathrm{rSO}_{2}$ value decreased. Our study investigates the serial changes in the cerebral $\mathrm{rSO}_{2}$ value during ICU after an ROSC treatment is currently ongoing. In the future, additional studies should be performed to investigate the relationship between the

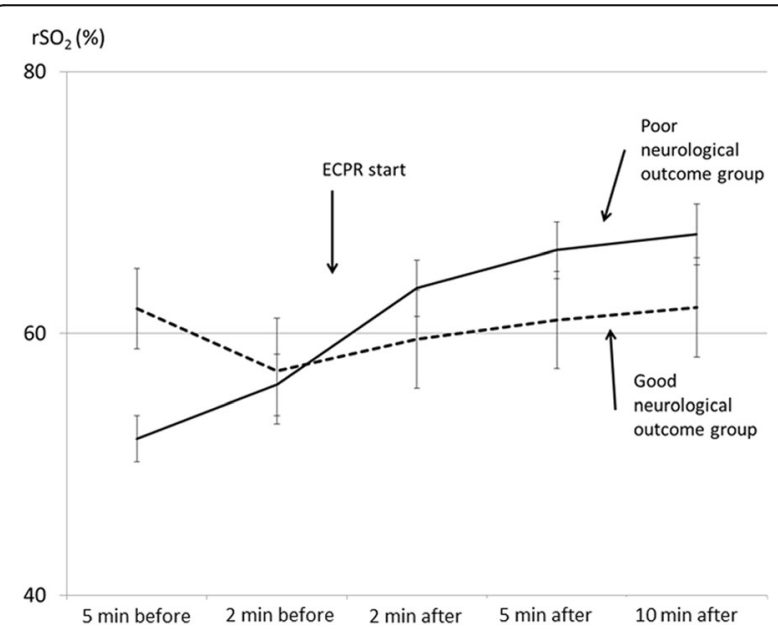

Fig. 2 The relationship between cerebral regional oxygen saturation $\left(\mathrm{rSO}_{2}\right)$ during extracorporeal cardiopulmonary resuscitation (ECPR) and the neurological outcome serial changes in the cerebral $\mathrm{rSO}_{2}$ value after an $\mathrm{ROSC}$ and the neurological outcome.

A recent review on ECPR revealed that the outcome of ECPR in patients with in-hospital cardiac arrest was satisfactory, with good survival rates and good neurological outcome [14]. However, it is more challenging to achieve satisfactory ECPR results in OHCA patients, and a good outcome can only be obtained in $15-20 \%$ of the patients, provided that the time from cardiac arrest to the initiation of ECPR is shorter than $60 \mathrm{~min}$. Our results may be useful for helping to establish a new ECPR strategy for cardiac arrest patients. If we can predict the neurological outcome during ECPR, we might be able to develop innovative methods to further improve the neurological outcome of these patients.

The present study is associated with some limitations. Firstly, the present study is a single-centre, retrospective study with a small population. There was no ECPR protocol and the application of ECPR depended on the physician's decision. Furthermore, it was not possible to evaluate the cerebral $\mathrm{rSO}_{2}$ value in all of the patients who underwent ECPR during this study period. The number of CPA cases was 420 during the study period. Second, only the patients whose cerebral $\mathrm{rSO}_{2}$ values were recorded during resuscitation were included in the present study. So, we could not evaluate the relationship between the cerebral $\mathrm{rSO}_{2}$ values and the cardiac index, the timing of ROSC and blood pressure. In this study, all patients did not get ROSC during the evaluation of the cerebral $\mathrm{rSO}_{2}$. Third, we did not evaluate the relationship between the cerebral $\mathrm{rSO}_{2}$ values and the blood sample parameters such as the $\mathrm{SaO}_{2}, \mathrm{PaO}_{2}, \mathrm{PaCO}_{2}$, haematocrit, and lactate values. Fourth, we could not evaluate brain function such as electroencephalogram. Moreover, we did not evaluate the cerebral $\mathrm{rSO}_{2}$ values in the pre-hospital setting. 


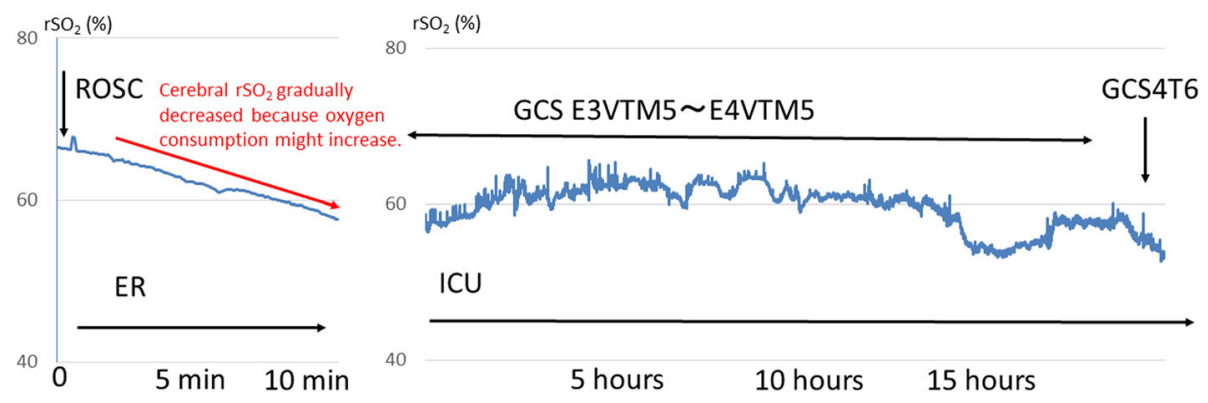

Fig. 3 The serial change in the cerebral regional oxygen saturation of a 74-year-old male patient during ICU treatment after the ROSC. When we started cerebral $\mathrm{rSO}_{2}$ measurement in this patient, the cerebral $\mathrm{rSO}_{2}$ value was $66 \%$; it gradually fell to $57 \%$ after 12 min. His neurological outcome was good. We think that the ROSC led to the recovery of the cerebral blood flow, and because the oxygen consumption of patients with a good neurological outcome might increase, the cerebral $\mathrm{rSO}_{2}$ value can be expected to decrease. ER emergency room, GCS Glasgow Coma Scale, ICU intensive care unit, $\mathrm{ROSC}$ return of spontaneous circulation, $\mathrm{rSO}_{2}$ regional saturation of oxygen

Recently, we developed a portable $\mathrm{rSO}_{2}$ monitor (HAND ai TOS $^{\circ}$; TOSTEC Co.), which is $170 \times 100 \times 50 \mathrm{~mm}$ in size and $600 \mathrm{~g}$ in weight and which is small enough to carry in the pre-hospital settings. Thus, we can now measure the pre-hospital $\mathrm{rSO}_{2}$ values [8]. There is a need for a prospective multi-centre study that includes measurements from the pre-hospital setting.

\section{Conclusions}

The cerebral $\mathrm{rSO}_{2}$ value during ECPR may predict the neurological outcome. The further evaluation of the validity of cerebral $\mathrm{rSO}_{2}$ monitoring during ECPR may lead to a new resuscitation strategy.

\section{Acknowledgements}

We gratefully acknowledge the devoted cooperation of the medical staff in the Traumatology and Critical Care Medical Center, National Hospital Organization Osaka National Hospital.

\section{Funding}

This work was supported by Grants-in-Aid for Scientific Research from the Ministry of Education, Culture, Sports, Science, and Technology in Japan (no. 15H05007).

\section{Availability of data and materials}

All data generated or analysed during this study are included in this published article.

\section{Authors' contributions}

$\mathrm{NE}, \mathrm{TH}, \mathrm{TS}$, and $\mathrm{MO}$ designed the study. NE, AW, TN, and DS collected and generated the data. NE, TH, TS, AW, TN, NM, and MO analysed the data. NE and TH wrote the first draft. TS, NM, MO, DS, and TS helped to draft the manuscript. All of the authors read and approved the final manuscript.

\section{Competing interests}

The authors declare that they have no competing interests.

\section{Consent for publication}

We could not obtain consent from all the patients because the subjects were all in CPA.

\section{Ethics approval and consent to participate}

This study was approved by the Ethics Committee of National Hospital Organization Osaka National Hospital (Osaka, Japan), and the institutional review board waived the need for informed consent because the subjects were all in $\mathrm{CPA}$ and this $\mathrm{rSO}_{2}$ monitor was non-invasive for patients.

\section{Author details}

${ }^{1}$ Traumatology and Critical Care Medical Center, National Hospital Organization Osaka National Hospital, 2-1-14 Hoenzaka Chuo-ku, Osaka, Osaka 540-0006, Japan. ${ }^{2}$ Department of Traumatology and Acute Critical Medicine, Osaka University Graduate School of Medicine, 2-15 Yamadaoka, Suita, Osaka 565-0871, Japan.

Received: 11 November 2016 Accepted: 18 February 2017 Published online: 23 February 2017

\section{References}

1. Kitamura T, Iwami T, Kawamura T, Nitta M, Nagao K, Nonogi H, et al. Nationwide improvements in survival from out-of-hospital cardiac arrest in Japan. Circulation. 2012;126:2834-43.

2. Berdowski J, Berg RA, Tijssen JG, Koster RW. Global incidences of out-ofhospital cardiac arrest and survival rates: systematic review of 67 prospective studies. Resuscitation. 2010;81:1479-87.

3. Nakahori Y, Shimizu K, Shiozaki T, Ogura H, Tasaki O, Kuwagata Y, et al. The change of cerebral $\mathrm{rSO}_{2}$ during cardiopulmonary resuscitation. Crit Care Med. 2008;36:A152.

4. Nakahori Y, Hirose T, Shiozaki T, Ogawa Y, Ohnishi M, Fujimi S, et al. Serial changes in values of cerebral regional saturation of oxygen $\left(\mathrm{rSO}_{2}\right)$ during resuscitation in patients with out-of-hospital cardiac arrest. Nihon Kyukyu lgakukai Zasshi. 2013;24:774-80 (Abstract in English).

5. Ito N, Nishiyama K, Callaway CW, Orita T, Hayashida K, Arimoto H, et al. Noninvasive regional cerebral oxygen saturation for neurological prognostication of patients with out-of-hospital cardiac arrest: a prospective multicenter observational study. Resuscitation. 2014;85:778-84.

6. Hayashida K, Nishiyama K, Suzuki M, Abe T, Orita T, Ito N, et al. Estimated cerebral oxyhemoglobin as a useful indicator of neuroprotection in patients with post-cardiac arrest syndrome: a prospective, multicenter observational study. Crit Care. 2014;18:500

7. Nishiyama K, Ito N, Orita T, Hayashida K, Arimoto H, Beppu S, et al. Regional cerebral oxygen saturation monitoring for predicting interventional outcomes in patients following out-of-hospital cardiac arrest of presumed cardiac cause: a prospective, observational, multicentre study. Resuscitation. 2015;96:135-41.

8. Tajima G, Shiozaki T, Izumino H, Yamano S, Hirao T, Inokuma T, et al. Portable system for monitoring of regional cerebral oxygen saturation during prehospital cardiopulmonary resuscitation: a pilot study. Acute Med Surg. 2015;2:48-52.

9. Hazinski MF, Nolan JP, Billi JE, Böttiger BW, Bossaert L, de Caen AR, et al. Part 1: Executive summary: 2010 International Consensus on

Cardiopulmonary Resuscitation and Emergency Cardiovascular Care Science with Treatment Recommendations. Circulation. 2010;122:S250-75.

10. Sanfilippo F, Serena G, Corredor C, Benedetto U, Maybauer M, Al-Subaie N, et al. Cerebral oximetry and return of spontaneous circulation after cardiac arrest: a systematic review and meta-analysis. Resuscitation. 2015;94:67-72.

11. Storm C, Leithner C, Krannich A, Wutzler A, Ploner CJ, Trenkmann L, et al. Regional cerebral oxygen saturation after cardiac arrest in 60 patients-a prospective outcome study. Resuscitation. 2014;85:1037-41. 
12. Taccone FS, Fagnoul D, Rondelet B, Vincent IL, de Backer D. Cerebral oximetry during extracorporeal cardiopulmonary resuscitation. Crit Care. 2013;17:409.

13. Yagi T, Nagao K, Sakatani K, Kawamorita T, Soga T, Kikushima K, et al. Changes of cerebral oxygen metabolism and hemodynamics during ECPR with hypothermia measured by near-infrared spectroscopy: a pilot study. Adv Exp Med Biol. 2013;789:121-8.

14. Fagnoul D, Combes A, De Backer D. Extracorporeal cardiopulmonary resuscitation. Curr Opin Crit Care. 2014;20:259-65.

Submit your next manuscript to BioMed Central and we will help you at every step:

- We accept pre-submission inquiries

- Our selector tool helps you to find the most relevant journal

- We provide round the clock customer support

- Convenient online submission

- Thorough peer review

- Inclusion in PubMed and all major indexing services

- Maximum visibility for your research

Submit your manuscript at www.biomedcentral.com/submit 